\title{
Prodrug Nanomedicine Inhibits Chemotherapy- Induced Proliferative Burst by Altering the Deleterious Intercellular Communication
}

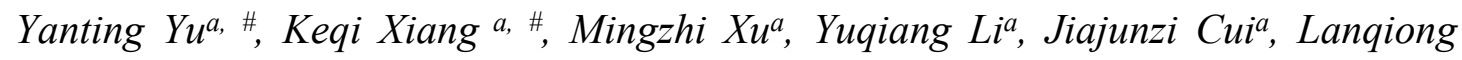

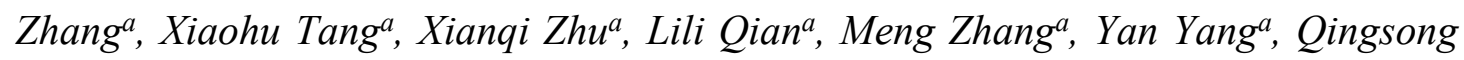
$Y^{a, *}$, Youqing Shen ${ }^{b}$, and Zhihua Gan ${ }^{a}$

${ }^{a}$ Beijing Laboratory of Biomedical Materials, The State Key Laboratory of Organicinorganic Composites, Beijing advanced innovation center for soft matter science and technology, College of Life Science and Technology, Beijing University of Chemical Technology, Beijing, 100029, China,

b Center for Bionanoengineering and Key Laboratory of Biomass Chemical Engineering of Ministry of Education, College of Chemical and Biological Engineering, Zhejiang University, Hangzhou 310027, China

*Corresponding author: Qingsong Yu, e-mail: yuqs@mail.buct.edu.cn.

\section{SUPPLEMENTARY METHODS}

Materials. Methoxy polyethylene glycol $(\mathrm{mPEG}, \mathrm{Mw}=5000 \mathrm{Da})$ was purchased from Sigma-Aldrich. D-alpha-tocopheryl succinate (VES), methacryloyl chloride (MA), 2- 
hydroxyethyl methacrylate (HEMA), 2,2'-dithiobis ethanol, 4-dimethylaminopyridine (DMAP), 1-(3-dimethylaminopropyl)-3-ethylcarbodiimide hydrochloride (EDC), dicyclohexyl carbodiimide (DCC), and glutathione (GSH) were purchased from J\&K Chemicals Inc. 7-ethyl-10-hydroxycamptothecin (SN38), doxorubicin (DOX), irinotecan and paclitaxel (PTX) were purchased from Beijing Huafenginfo United Co., Ltd. Fetal bovine serum (FBS), Dulbecco's Modified Eagle Medium (DMEM), and penicillin/streptomycin solution were purchased from Thermo Scientific. All other chemicals were purchased from commercial supplier and used without further purification. Poly(ethylene glycol) $(\mathrm{Mw}=5000 \mathrm{Da})$ macro chain transfer agent (PEGCTA) was prepared according to the literature reported method. ${ }^{1}$ PSSV and PCCV polymers were synthesized according to our reported procedures. ${ }^{2}$

Cell Lines and Cell Culture. Human breast cancer cell line (MCF-7), human cervical adenocarcinoma cell line (Hela), mouse fibroblasts (NIH-3T3) and human breast fibroblasts (Hs578T) were obtained from ATCC. GFP overexpressed MCF-7 cells (MCF-7-GFP) were obtained from Jennio Co., Ltd. All these cells were cultured in DMEM medium supplemented with $10 \%(\mathrm{v} / \mathrm{v}) \mathrm{FBS}$ and maintained at $37^{\circ} \mathrm{C}$ in a $5 \%$ $\mathrm{CO}_{2}$ atmosphere and $100 \%$ humidity. The paclitaxel resistant cell line (MCF-7/PTX) and cisplatin resistant cell line (Hela/CDDP) was established from their isogenetic cell line MCF-7 and Hela by increasing the concentration of paclitaxel or cisplatin in the culture medium in a stepwise manner over a period of 4 months. Drug concentration was gradually increasing from 2 to $20 \mathrm{nM}$. The cells were maintained in each concentration of paclitaxel for at least 2 weeks. 
Synthesis of SN38-VES prodrug (SV). ${ }^{3}$ The mixture of SN38 (1g, 2.5mmol), VES (2 $\mathrm{g}, 3.8 \mathrm{mmol})$ and anhydrous pyridine $(10 \mathrm{~mL})$ in $100 \mathrm{~mL}$ N,N-dimethylformide (DMF) was cooled on an ice bath. Then $20 \mathrm{~mL}$ DMF containing EDC $(0.95 \mathrm{~g}, 5.0 \mathrm{mmol})$ was added. The mixture was further stirred for $24 \mathrm{~h}$ at room temperature. DMF was removed under rotary evaporation and dichloromethane (DCM) was added. The organic phase was washed sequentially with water $(3 \times 20 \mathrm{~mL})$ and saturated sodium chloride $(80 \mathrm{~mL})$, and dried with anhydrous sodium sulfate. The crude product was then purified by silicagel column chromatography using petroleum ether/ethyl acetate as the eluent $(3 / 2, \mathrm{v} / \mathrm{v})$. Yield $2.01 \mathrm{~g}(87.1 \%)$. 


\section{Supplementary Figures}
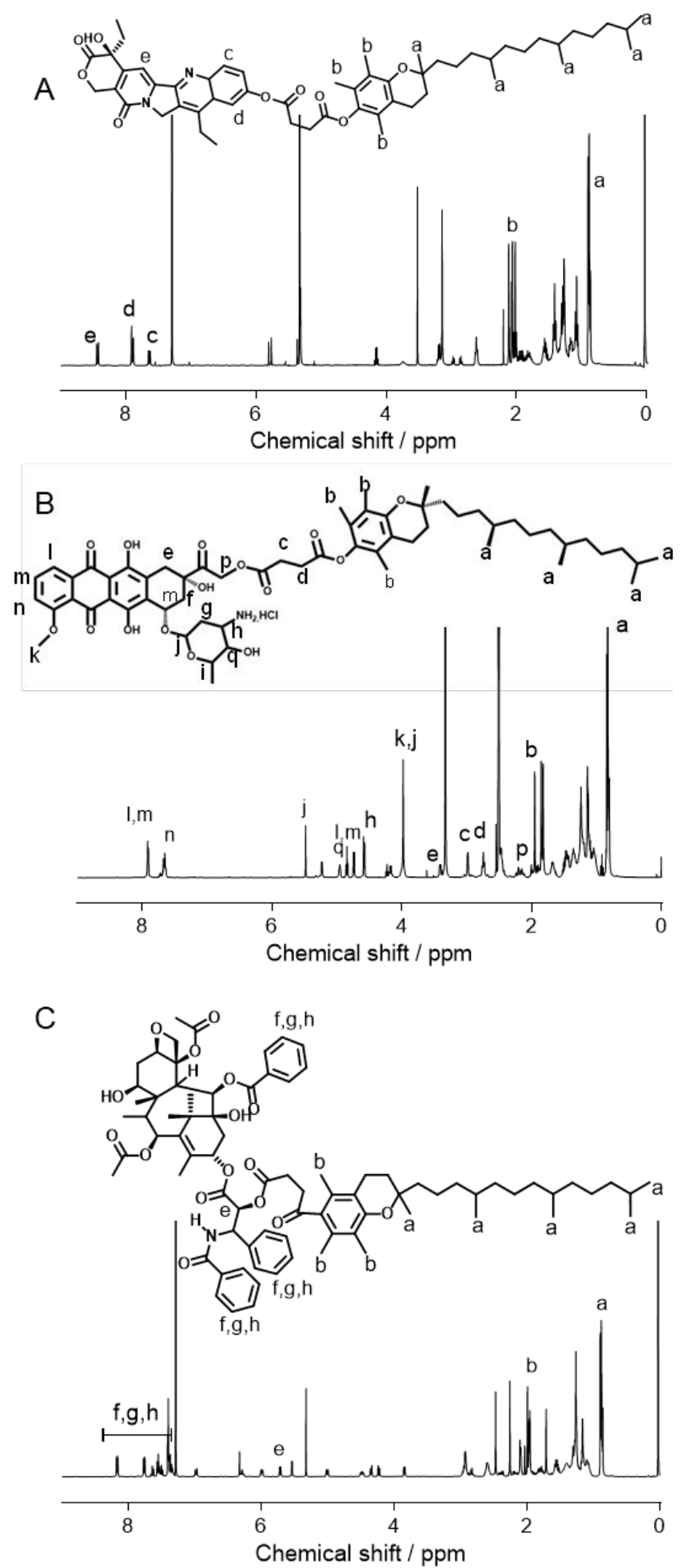

Figure S1. The ${ }^{1} \mathrm{H}$ NMR spectra of SN38-VES (A), DOX-VES (B), and PTX-VES (C) prodrug. 

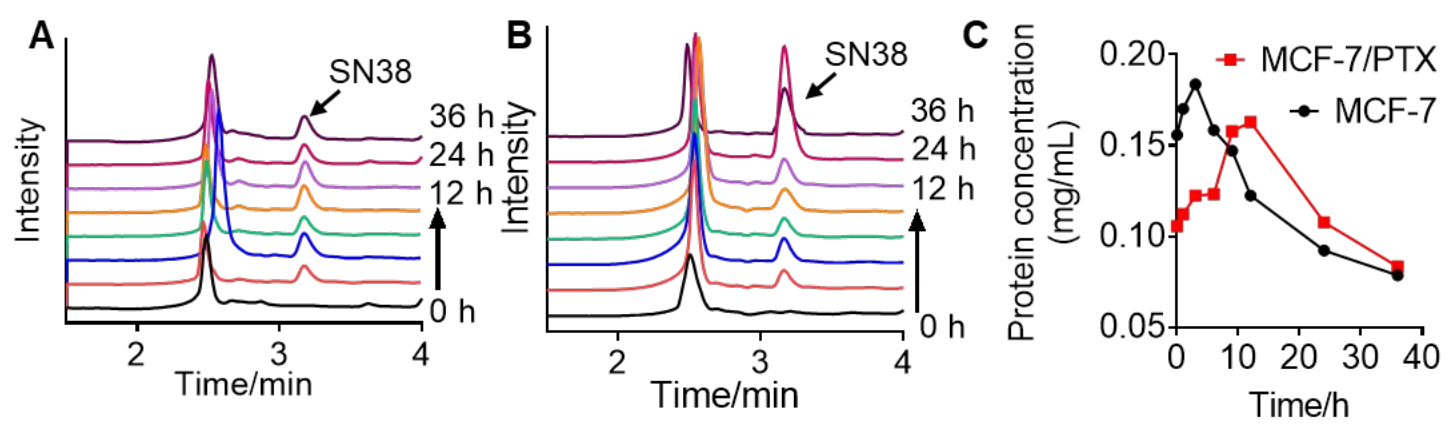

Figure S2. The HPLC elution curves of SN38 in MCF-7 (A) and MCF-7/PTX (B) cells after treated with SV prodrug for different time. (C) The alteration of intracellular protein content in MCF-7 and MCF-7/PTX cells after treated with SV prodrug for different time. The protein content was determined by standard BCA test.

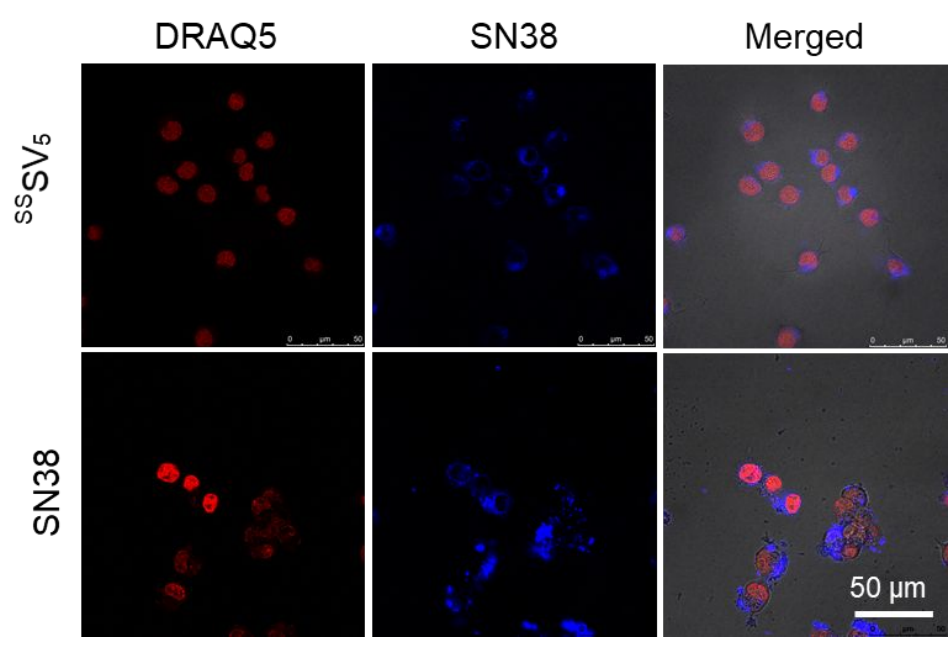

Figure S3. The intracellular trafficking of SN38 and ${ }^{{ }^{s}} \mathrm{SV}_{5}$ NPs in MCF-7/PTX cells. SN38 was shown in blue, cell nucleus was stained with DARQ5. The scale bar represents $50 \mu \mathrm{m}$. 

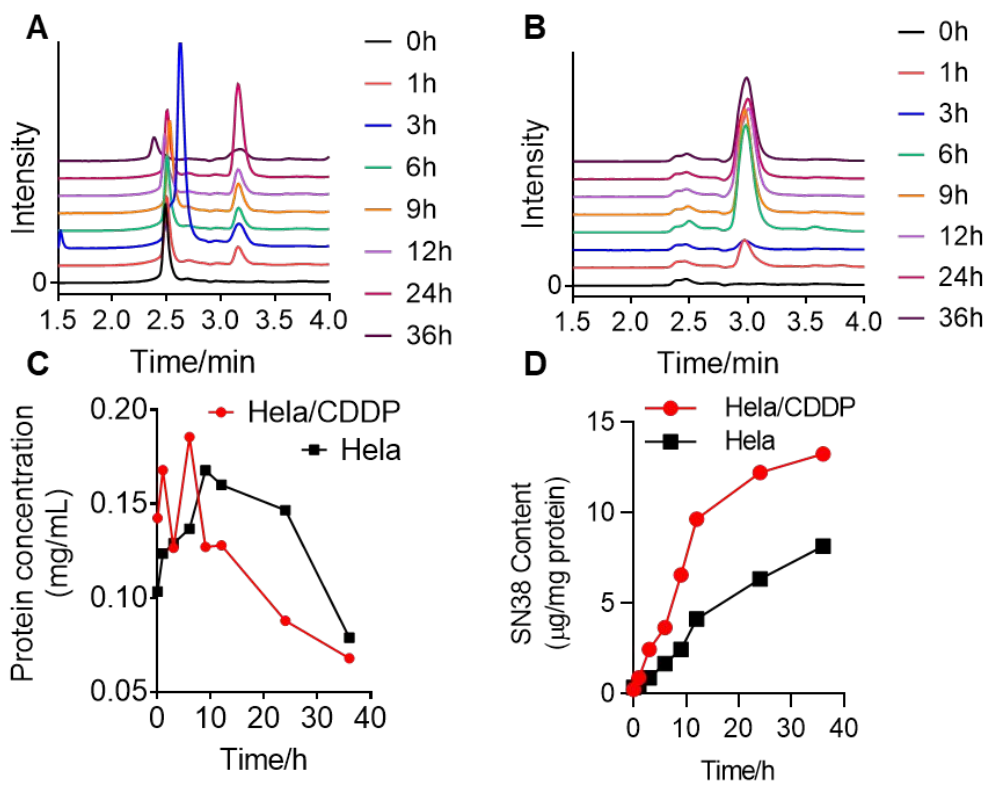

Figure S4. The HPLC elution curves of Hela (A) and Hela/DDP cells (B) after treated with SV NPs.

SN38 peak appeared at around $3 \mathrm{~min}$. (C) The alteration of intracellular protein content in MCF-7 and MCF-7/PTX cells after treated with SV prodrug for different time. The protein content was determined by standard BCA test. (D) The intracellular SN38 release kinetics in MCF-7/PTX and MCF-7 cells.

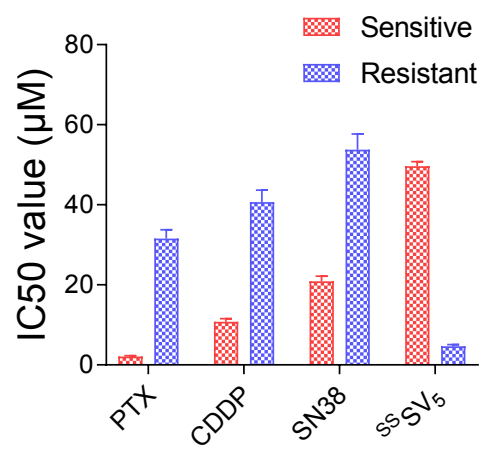

Figure S5. Cytotoxicity of various drugs against Hela (sensitive) and Hela/CDDP (resistant) cells. 
A

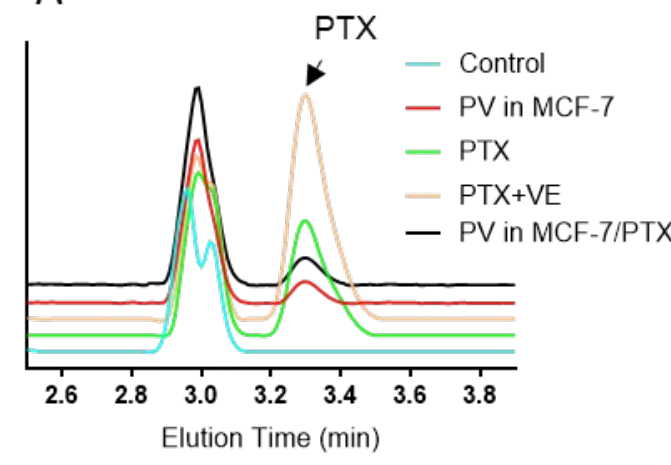

B

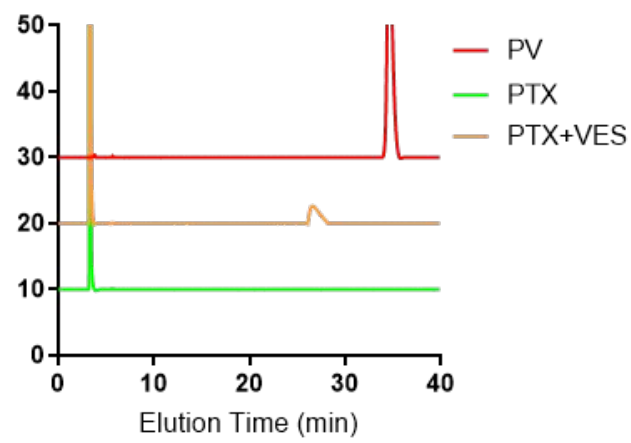

Figure S6. (A) The HPLC elution curves of MCF-7/PTX cells after treated with PV or PTX and

(B) the HPLC standard curves of PV, PTX and PTX+VES. 
a

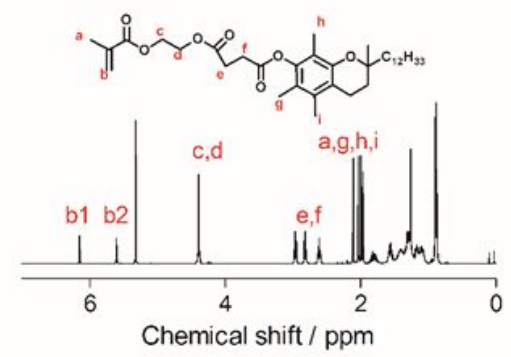

C

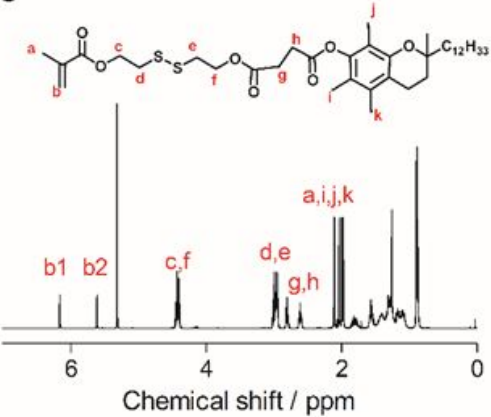

e

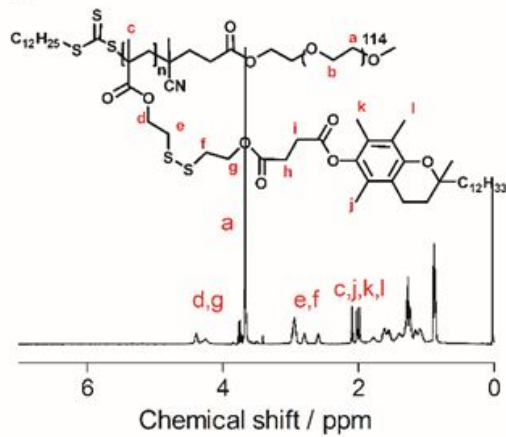

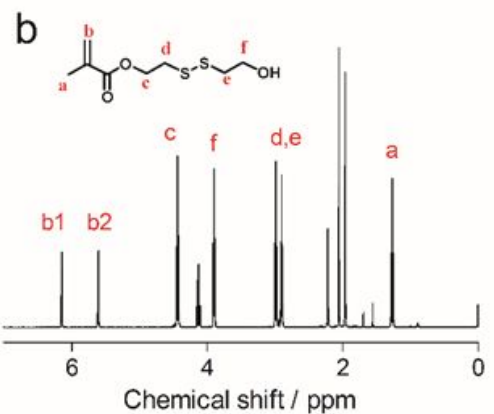

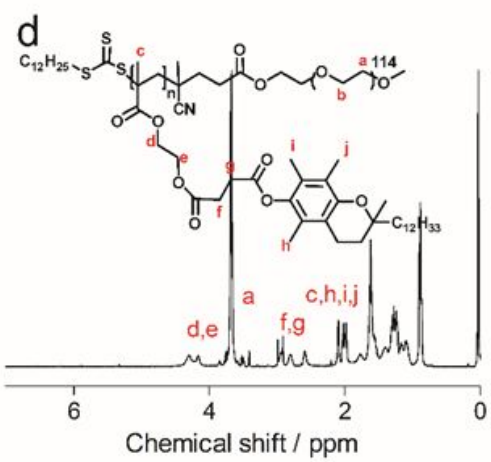

Figure S7. The ${ }^{1} \mathrm{H}$ NMR spectra of $\operatorname{HEMA-VE~(a),~MASSOH~(b),~MASSVE~(c),~}$ PEG $_{5 \mathrm{k}}$-b$\operatorname{PMACCV}_{6 \mathrm{k}}\left(\mathrm{PCCV}_{6 \mathrm{k}}\right)(\mathrm{d})$, and $\mathrm{PEG}_{5 \mathrm{k}}-\mathrm{b}-\mathrm{PMASV}_{6 \mathrm{k}}\left(\mathrm{PSSV}_{6 \mathrm{k}}\right)(\mathrm{e})$. 


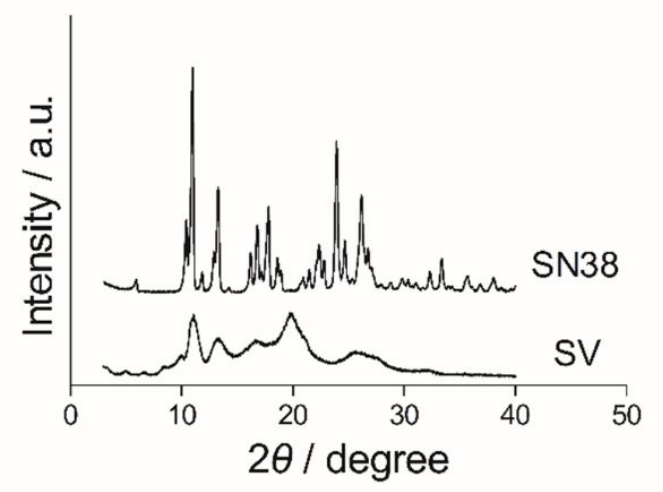

Figure S8. XRD spectrum of SN38 and SV prodrug powders.
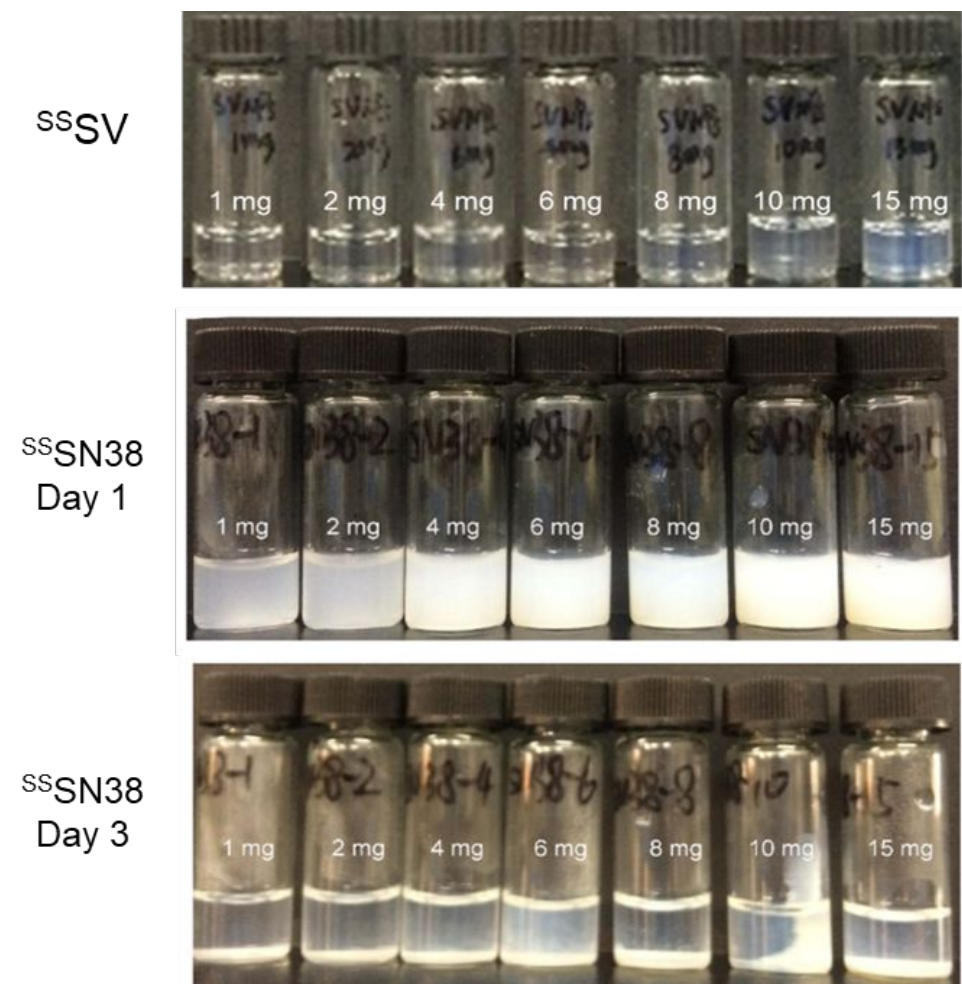

Figure S9. The appearance and stability of ${ }^{\mathrm{SS}} \mathrm{SV}$ or ${ }^{\mathrm{SS}} \mathrm{SN} 38 \mathrm{NPs}$. 


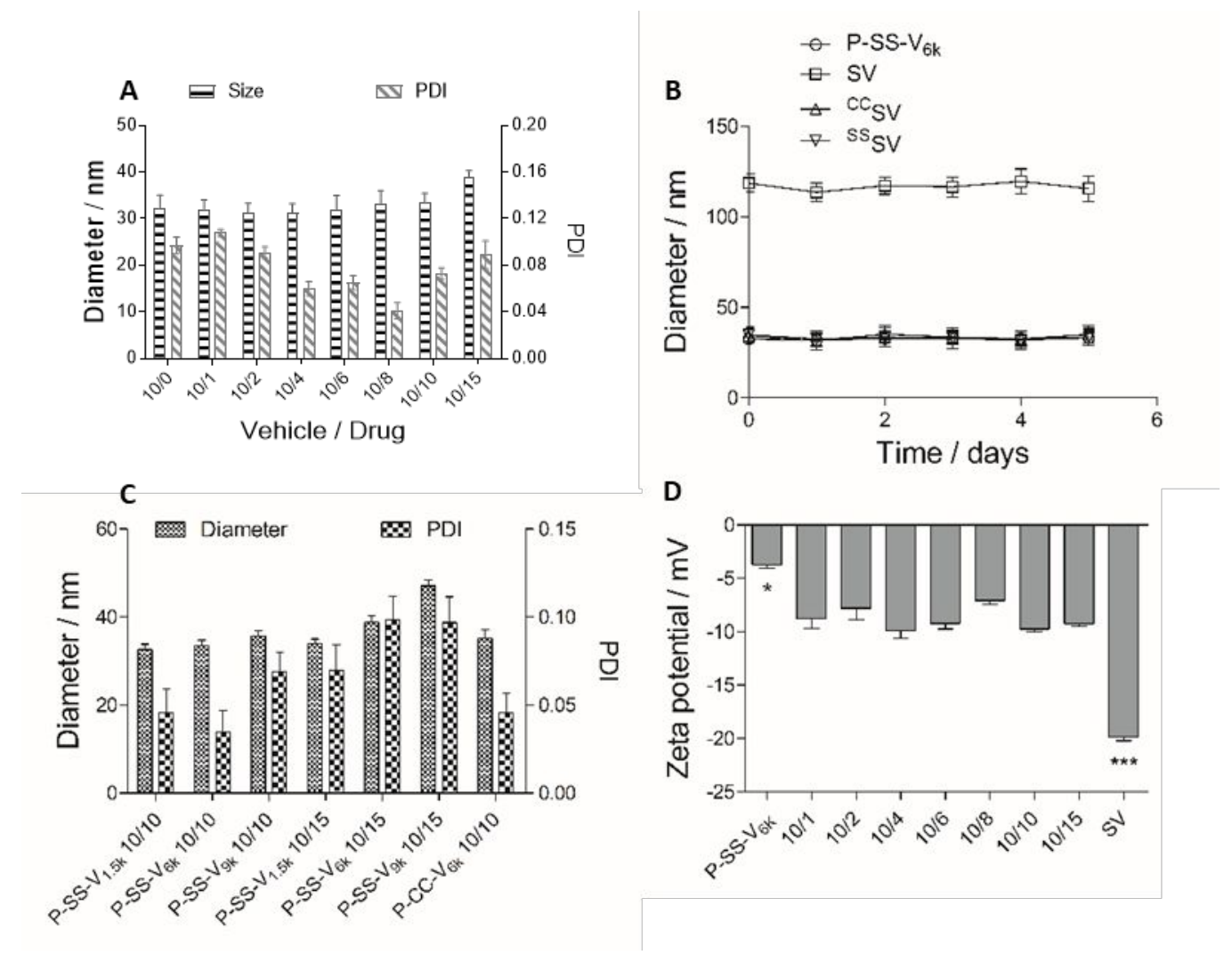

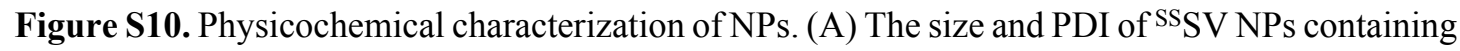
$10 \mathrm{mg} \mathrm{PSSV}_{6 \mathrm{k}}$ polymer and various amount of SV prodrug. (B) The stability assay of NPs during 5 days' incubation in $30 \%$ FBS. (C) The size and size distribution of NPs made from copolymers with different hydrophobic block. (D) The zeta potentials of NPs with different DLC. ${ }^{*}<0.05 \mathrm{PSSV}_{6 \mathrm{k}}$ compared with the rest groups; $* * * \mathrm{P}<0.001$ for $\mathrm{SV}$ compared with the rest groups, $\mathrm{n}=3$.

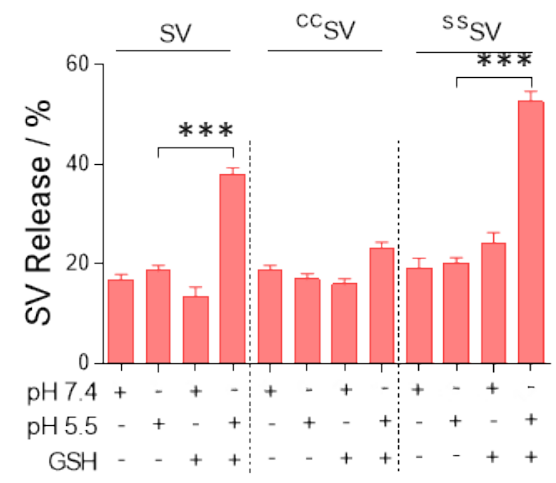

Figure S11. The cumulative SV release from various NPs after $72 \mathrm{~h}$ incubation at different $\mathrm{pH}$ 
(5.5 or 7.4) in the presence or absence of $10 \mathrm{mM} \mathrm{GSH}$ or $100 \mathrm{U} / \mathrm{mL}$ esterase. Error bar represented the s.d. $(\mathrm{n}=3) . * * \mathrm{P}<0.01 ; * * * \mathrm{P}<0.001$.
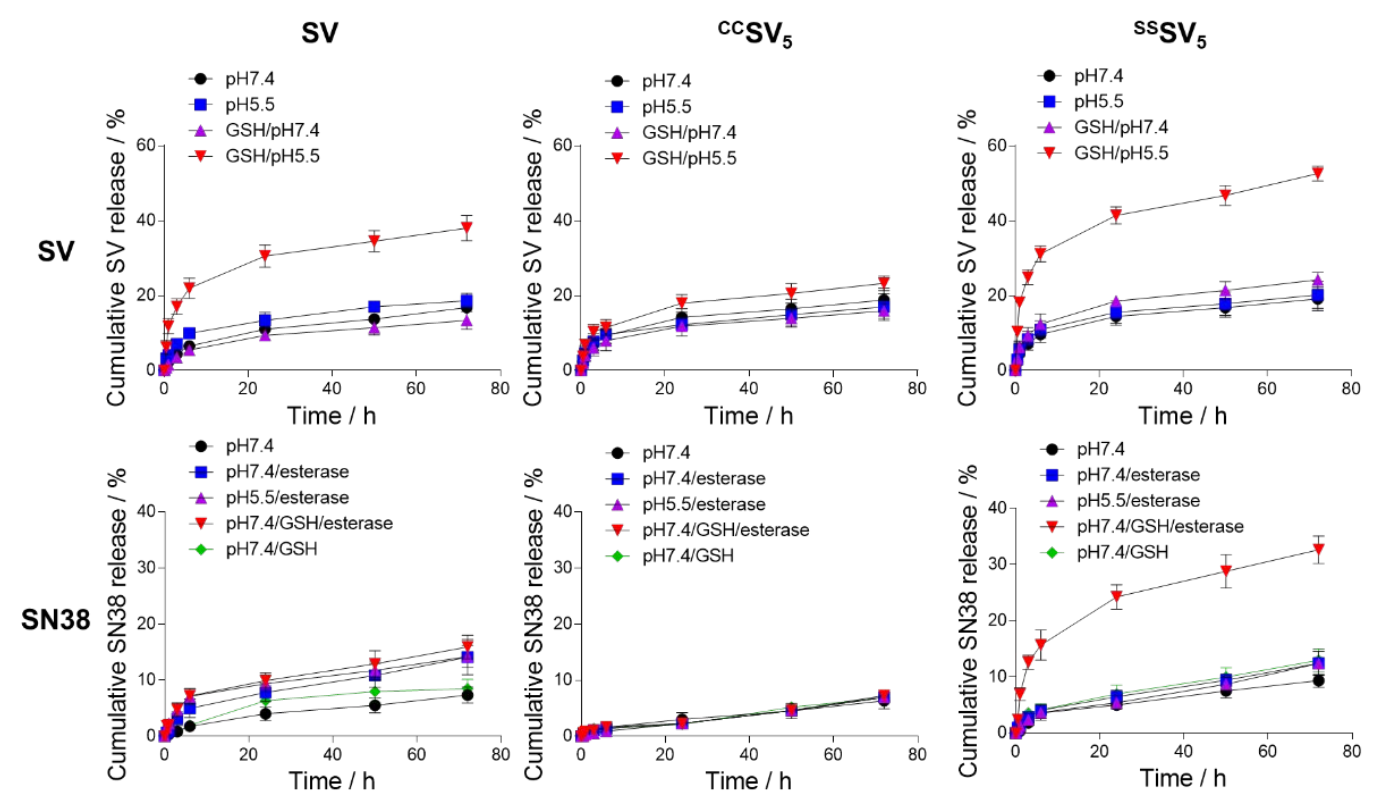

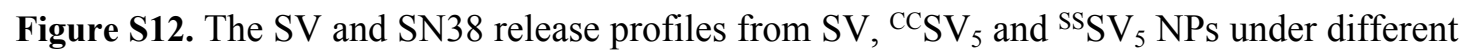
conditions.

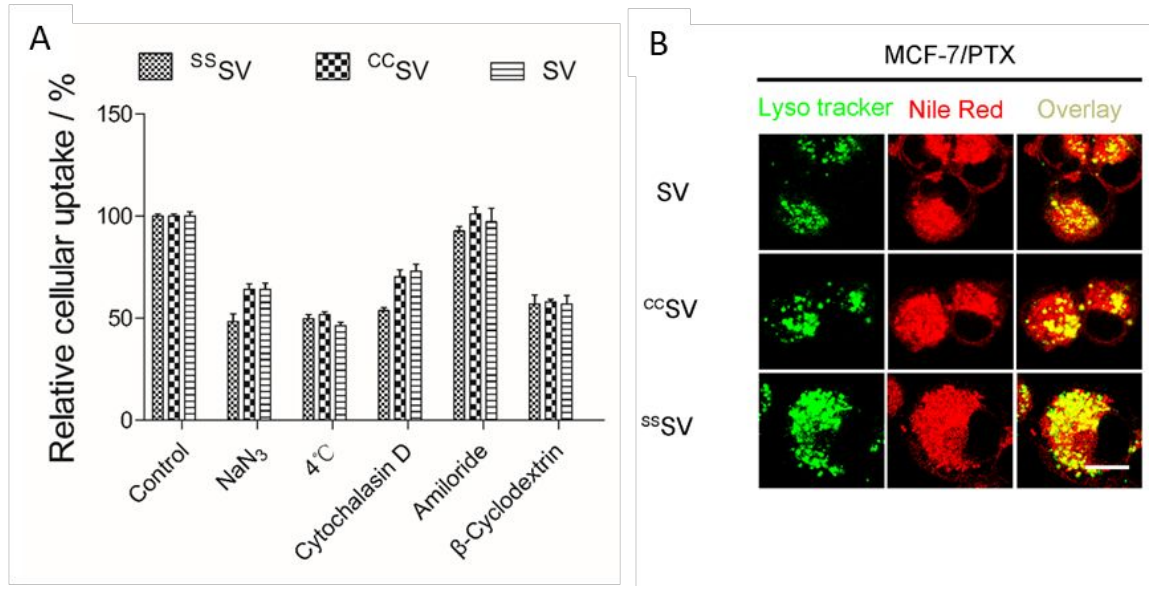

Figure S13. (A). The endocytic pathway analysis of various NPs by MCF-7/PTX cells. Cells were pretreated with various conditions or inhibitors, and then with Nile Red labelled NPs. (B) The intracellular trafficking of NPs in MCF-7/PTX cells. Nile Red labeled NPs were shown in red. 
Lysosomes were stained with LysoTracker ${ }^{\star}$ Green DND-26 and shown in green. The lysosomal co-localization was presented by the overlap between red and green fluorescence and shown in yellow.

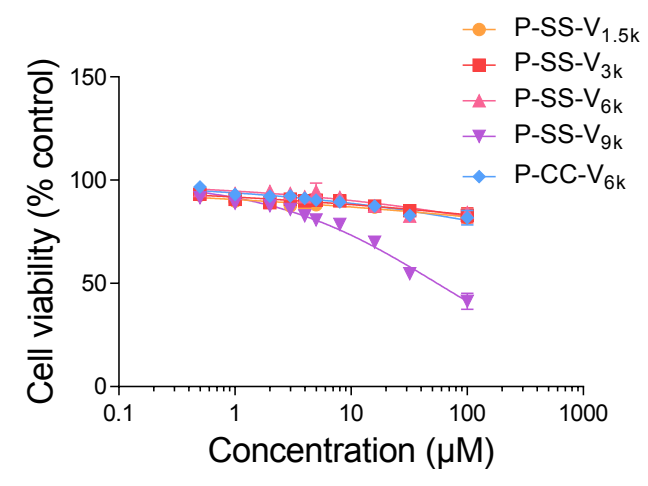

Figure S14. The cell viability of MCF-7/PTX cells treated with different concentration of various PSSV block copolymers.
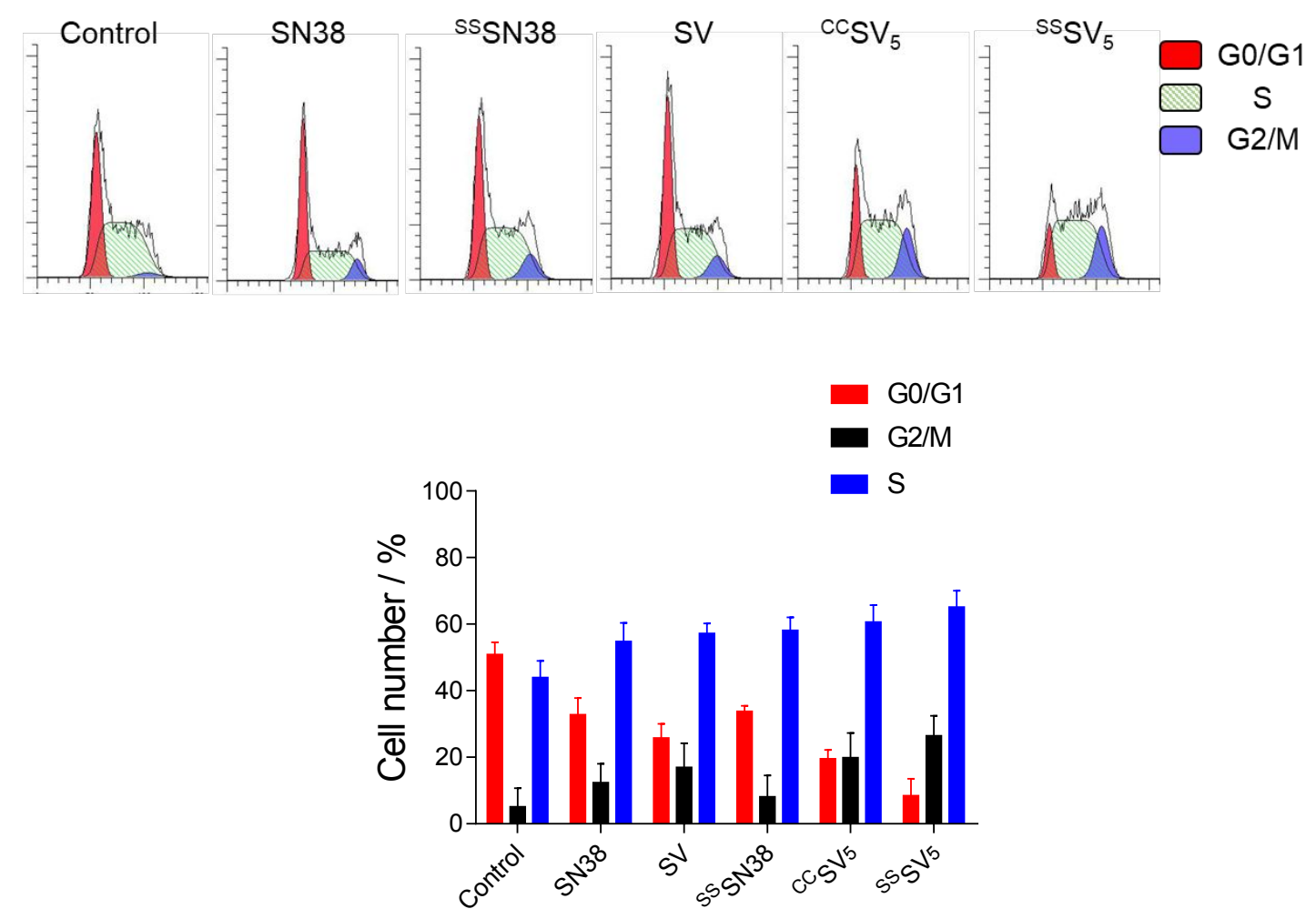
Figure S15. The cell cycle of MCF-7/PTX cells treated with various drugs.

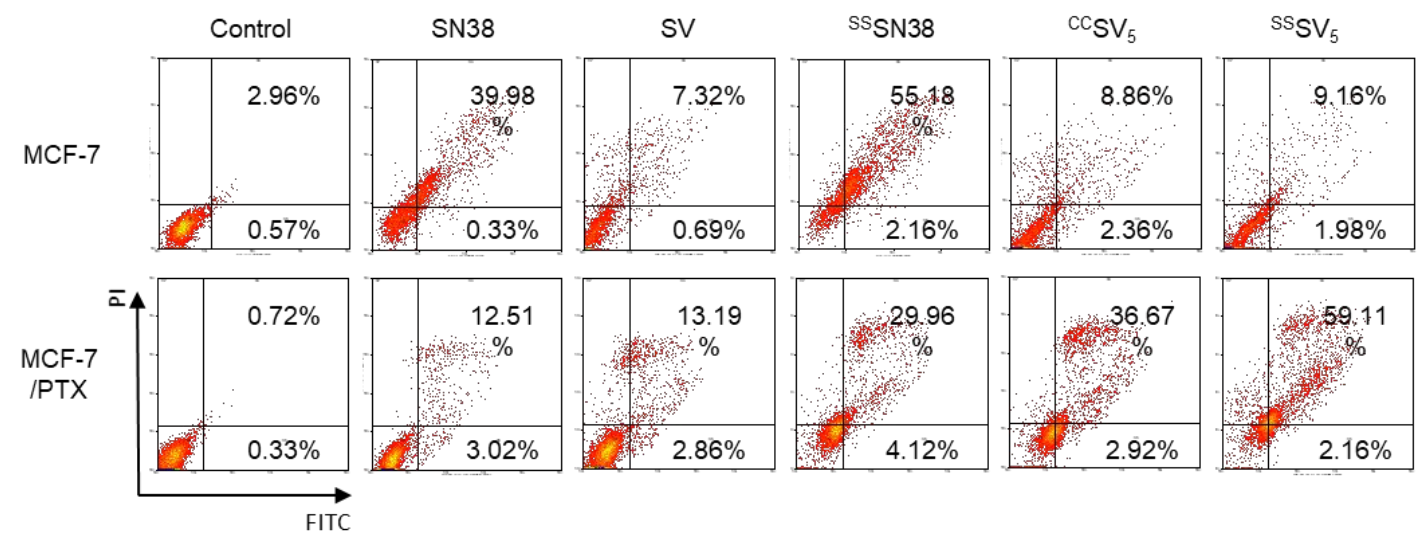

Figure S16. Apoptosis of MCF-7 and MCF-7/PTX cells after incubating with 1.0 $\mu \mathrm{M}$ of different formulations for $24 \mathrm{~h}$. Apoptotic cells were double-stained with Annexin V-FITC and propidine iodide (PI).

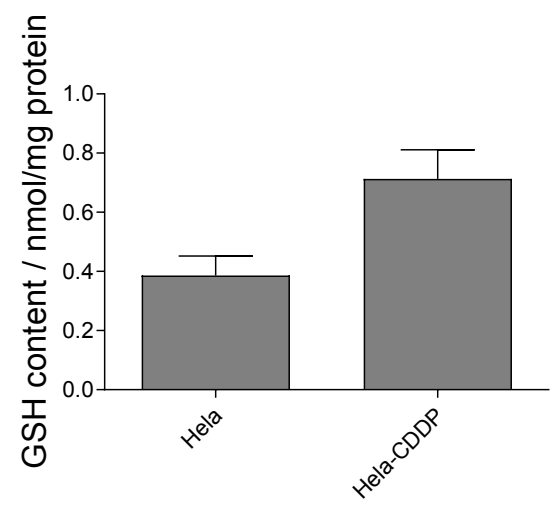

Figure S17. GSH content in Hela and Hela-CDDP cells. 


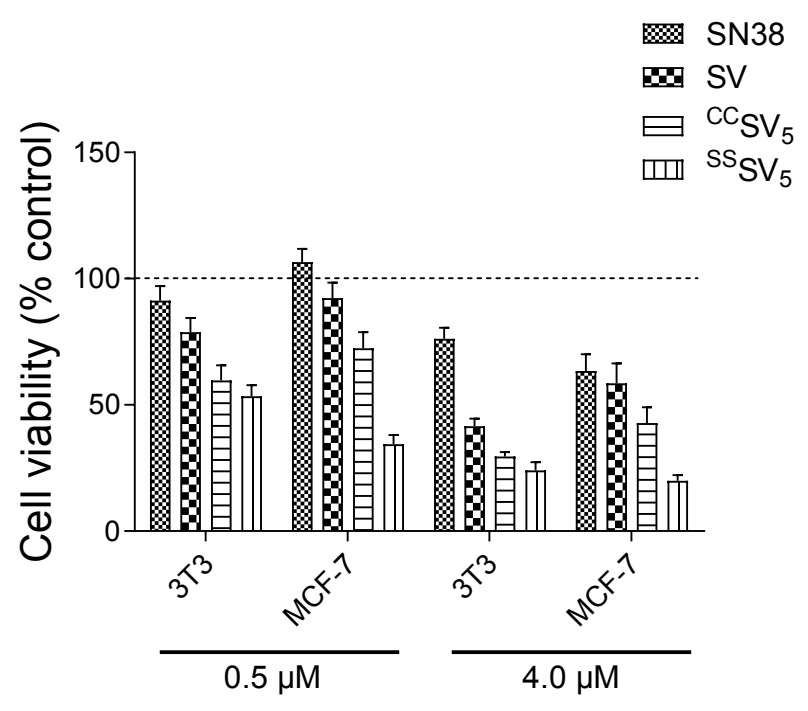

Figure S18. The quantified proliferation of MCF-7/PTX cells in different conditioned media (CM) which was quantified as the percentage of the corresponding drug-free CM. NIH-3T3 and MCF-7 cells were incubated with $0.5 \mu \mathrm{M}$ or $4.0 \mu \mathrm{M}$ of SN38, SV, ${ }^{\mathrm{CC}} \mathrm{SV}_{5}$ or ${ }^{\mathrm{SS}} \mathrm{SV}_{5}$ to prepare the CM.

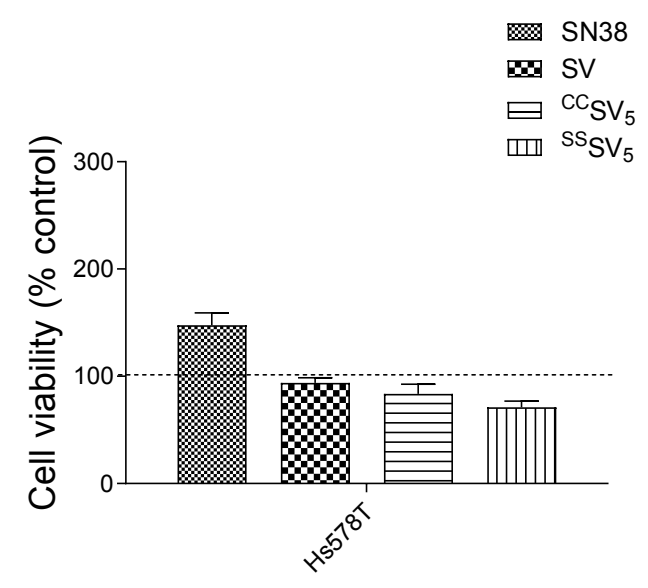

Figure S19. The quantified proliferation of MCF-7/PTX cells co-cultured with Hs578T cells in a trans-well plate under the presence of $0.1 \mu \mathrm{M} \mathrm{SN} 38, \mathrm{SV},{ }^{\mathrm{C} C} \mathrm{SV}_{5}$ or ${ }^{\mathrm{SS}_{\mathrm{SV}}}$. 

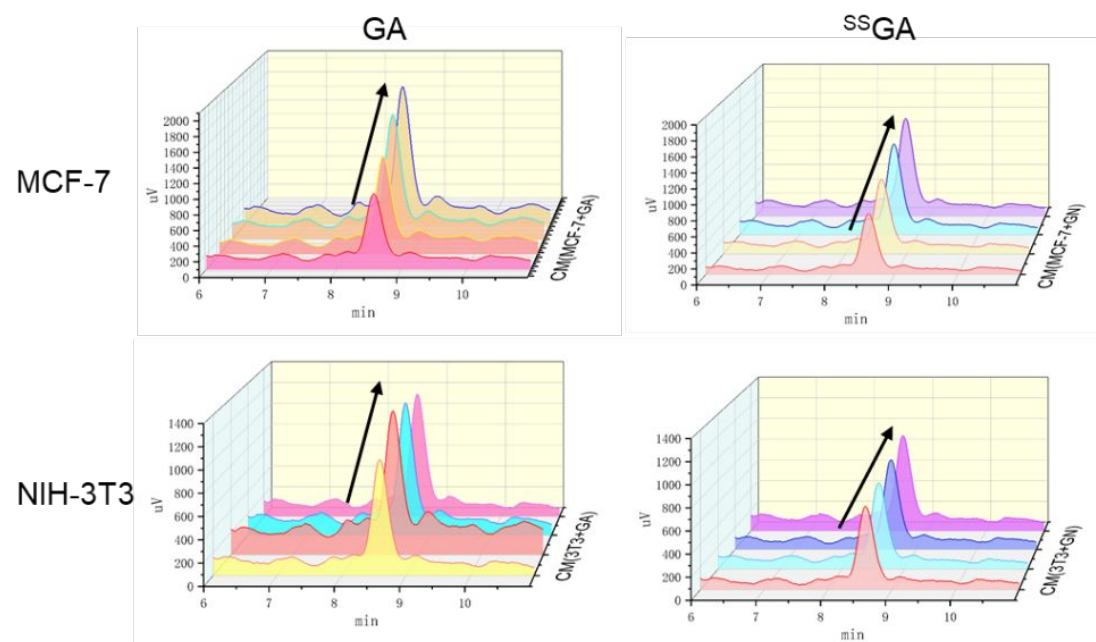

Figure S20. The elution profiles of residue GA in the CM of MCF-7 and NIH-3T3 cells after treated with $0.05,0.1,0.2,0.5 \mu \mathrm{M}$ of $\mathrm{GA}$ or ${ }^{\mathrm{SS}} \mathrm{GA}$.
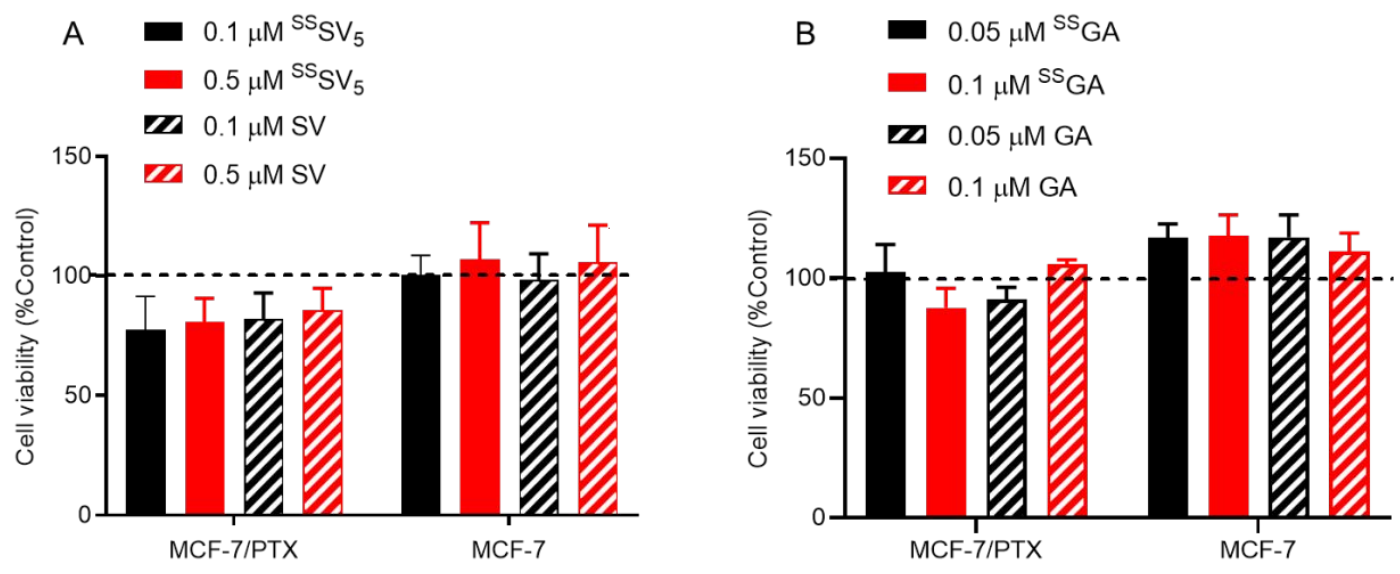

Figure S21. The quantified proliferation of MCF-7/PTX and MCF-7 cells in different conditioned media (CM(MCF-7/PTX)). MCF-7/PTX cells were incubated with $0.1 \mu \mathrm{M}, 0.5 \mu \mathrm{M}$ of SV or ${ }^{\mathrm{SS}} \mathrm{SV}_{5}$ and $0.05 \mu \mathrm{M}, 0.1 \mu \mathrm{M}$ of $\mathrm{GA}$ or ${ }^{\mathrm{SS}} \mathrm{GA}$ to prepare the $\mathrm{CM}$. 


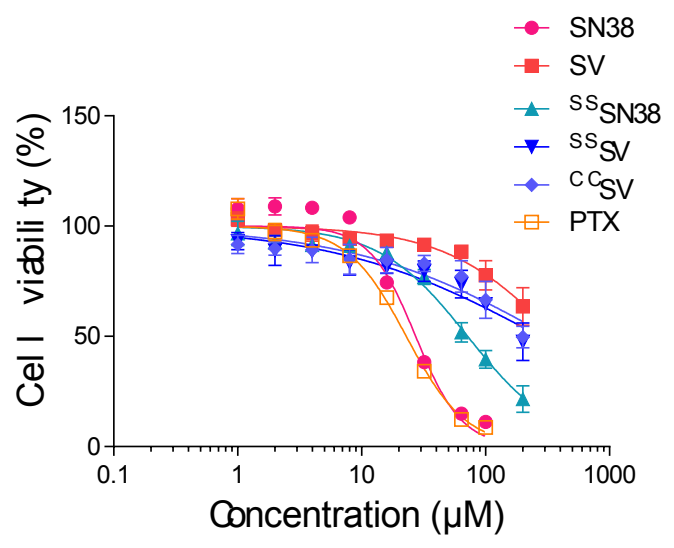

Figure S22. The concentration dependent cytotoxicity of various drugs against NIH-3T3 cells.

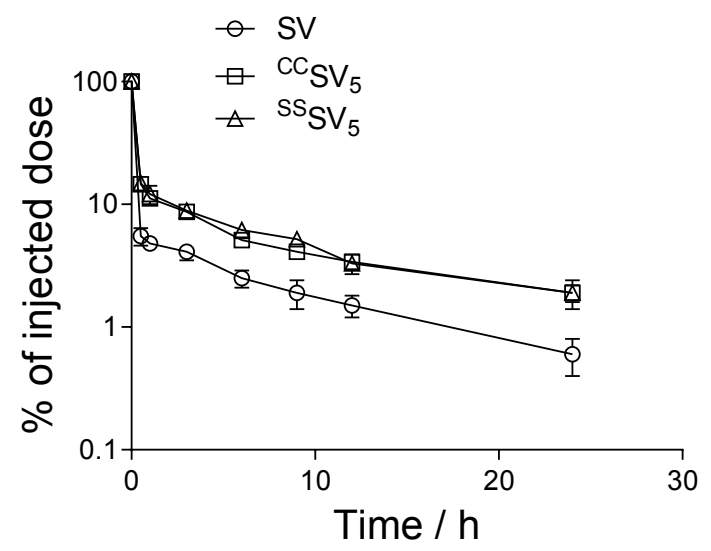

Figure S23. The blood clearance of $\mathrm{SV},{ }^{\mathrm{C}} \mathrm{SV}_{5},{ }^{\mathrm{SS}} \mathrm{SV}_{5} \mathrm{NPs}$ in MCF-7/PTX tumor bearing $\mathrm{BALB} / \mathrm{c}$ nude mice. 


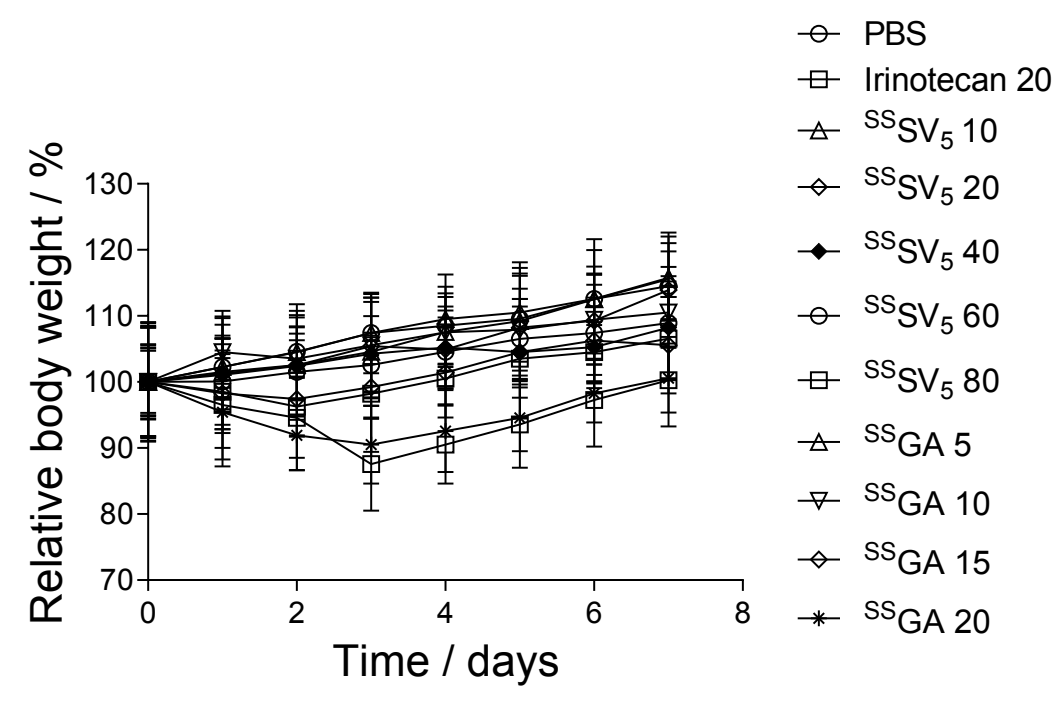

Figure S24. Body weight change of BALB/c mice after single injection of various formulations.

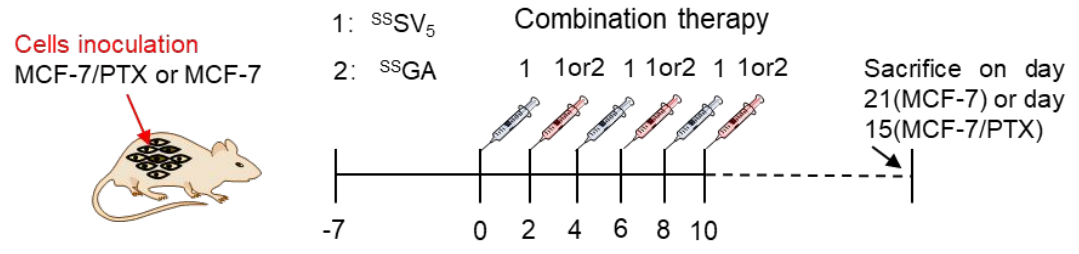

Figure S25. Schematic illustration of the treatment regime.

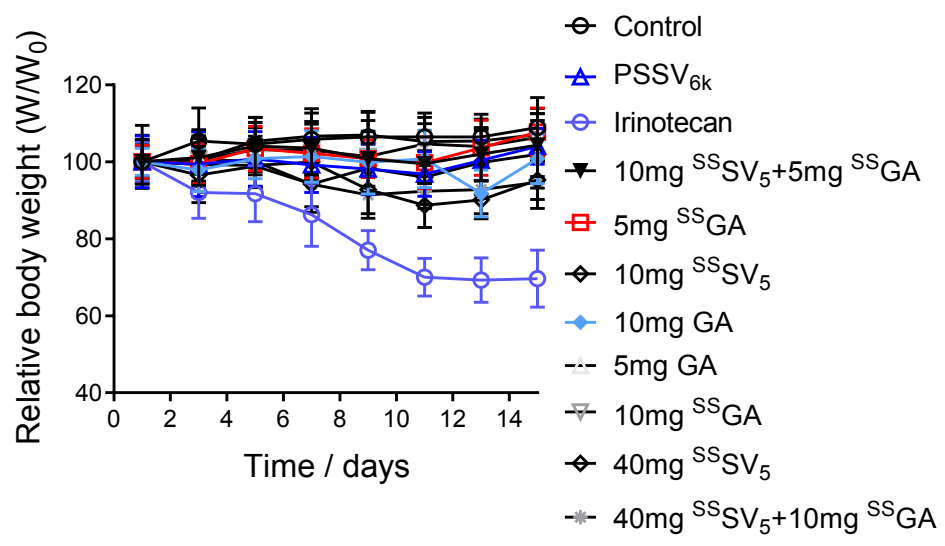

Figure S26. The relative body weight change of MCF-7/PTX tumor bearing mice after treatments with various drugs. 


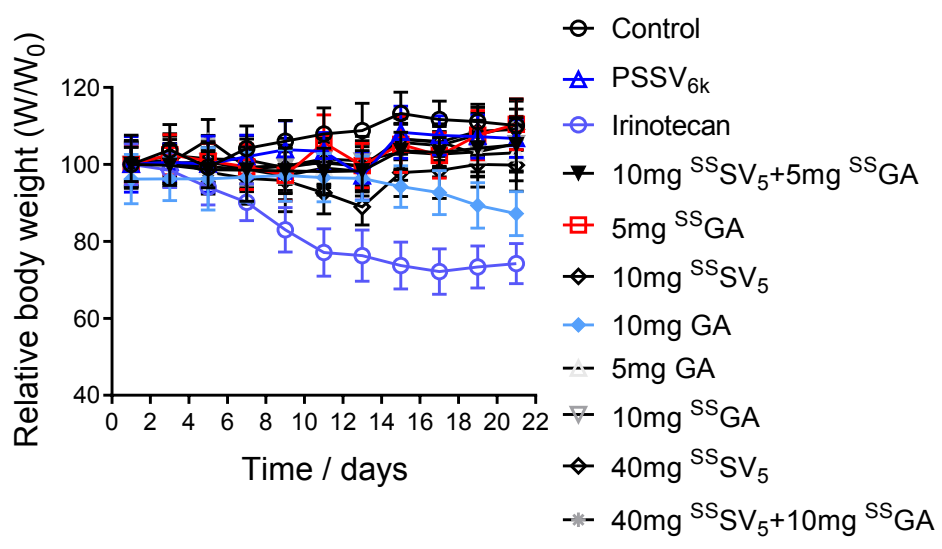

Figure S27. The relative body weight change of MCF-7 tumor bearing mice after treatments with various drugs. 


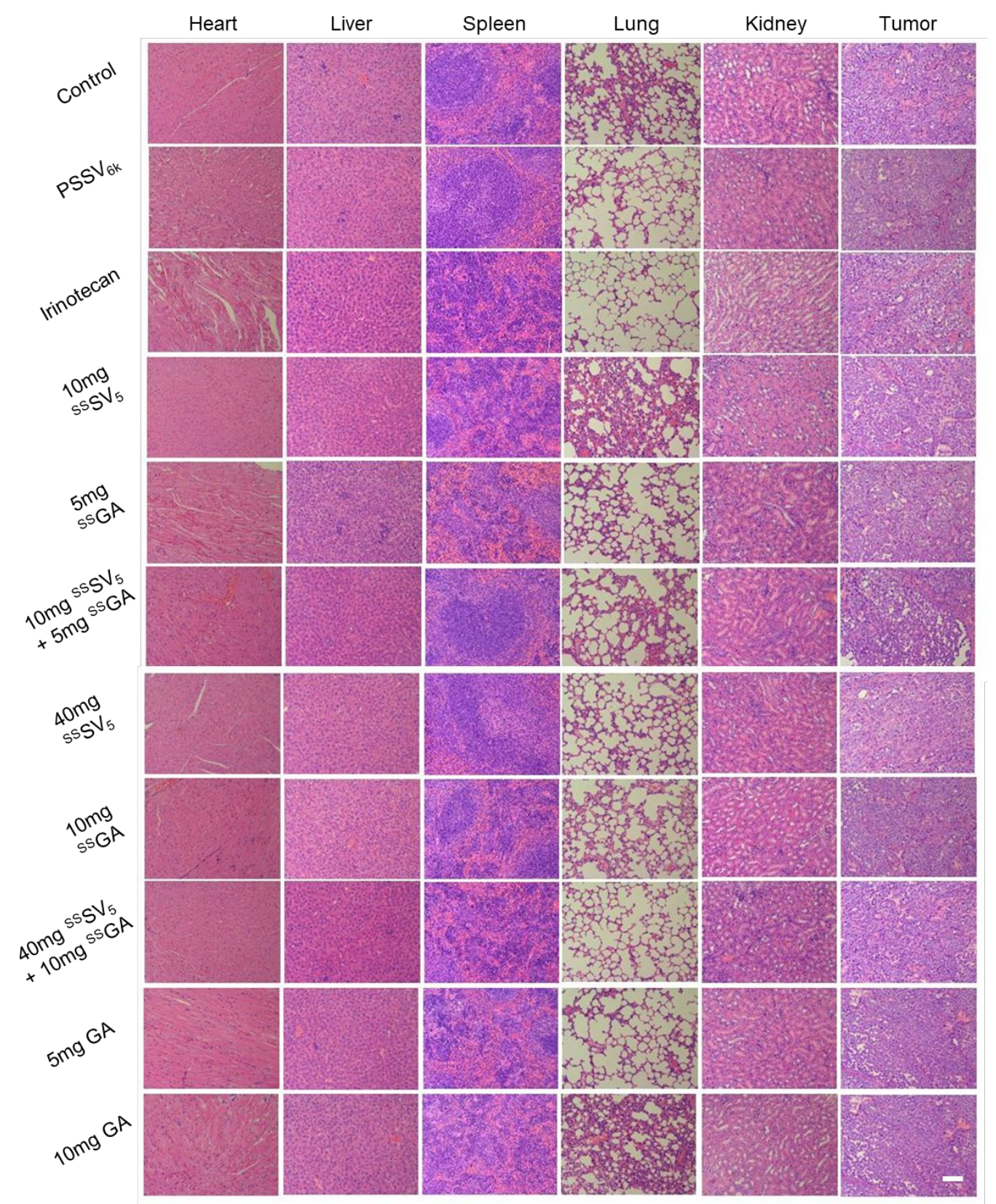

Figure S28. H\&E staining images of tumor and major organs such as heart, lung, liver, spleen and

kidney excised from MCF-7/PTX tumor bearing mice after the 15days tumor inhibition experiments. 


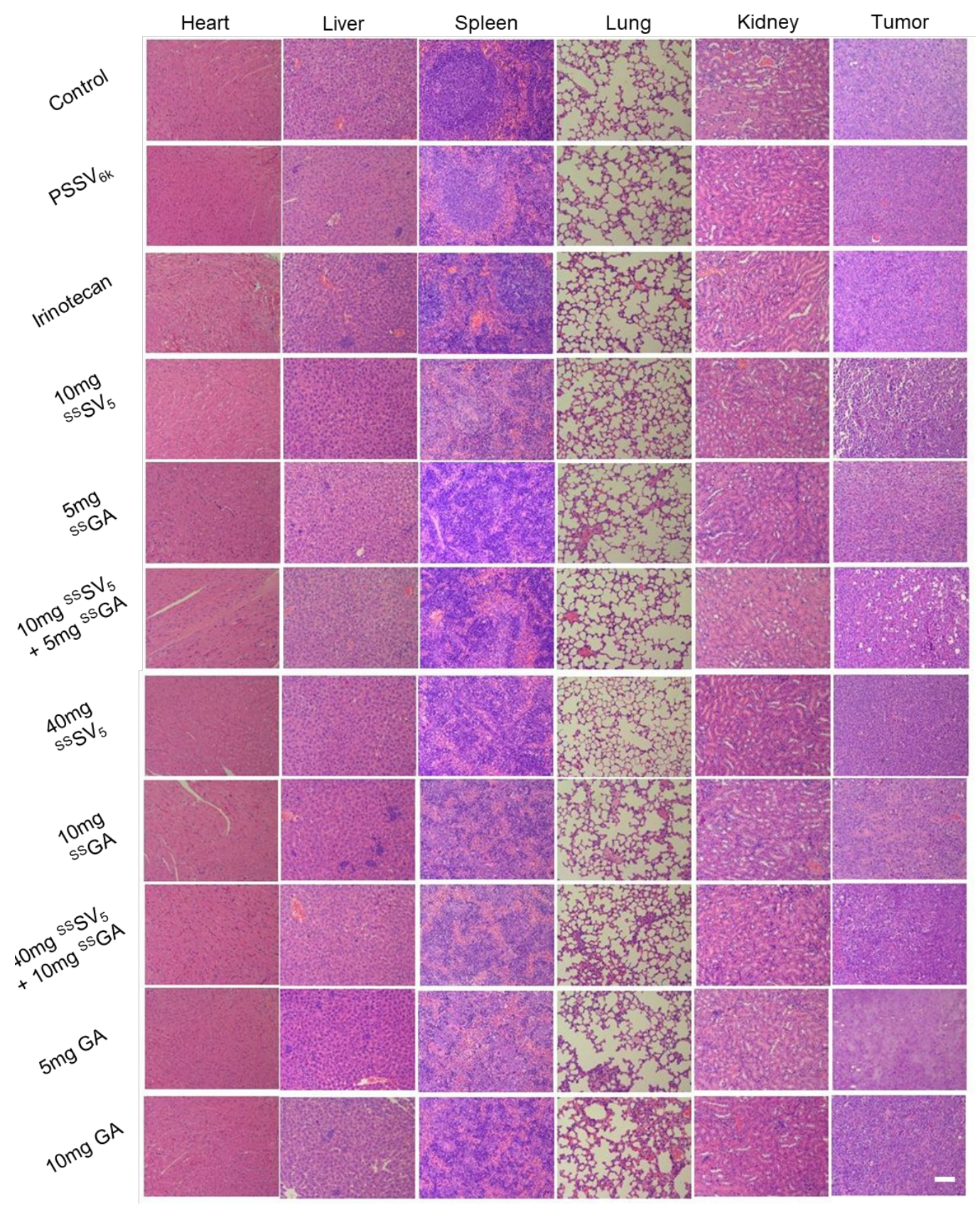

Figure S29. H\&E staining images of tumor and major organs such as heart, lung, liver, spleen and kidney excised from MCF-7 tumor bearing mice after the 22days tumor inhibition experiments. 
Table S1. Summary of molecular weight and molecular weight distribution of PEG Fk- $^{-b}$ PMASSV copolymers with different hydrophobic block.

\begin{tabular}{|c|c|c|c|c|c|}
\hline Sample & $\mathrm{M}_{\mathrm{PEG}}$ & $\mathrm{M}_{\mathrm{P}(\mathrm{MA}-\mathrm{SS}-\mathrm{VE})^{\mathrm{a}}}$ & $\mathrm{Mw}^{\mathrm{b}}$ & $\mathrm{Mn}^{\mathrm{b}}$ & $\mathrm{PDI}^{\mathrm{b}}$ \\
\hline $\operatorname{PSSV}_{1.5 \mathrm{k}}$ & 5000 & 1800 & 9800 & 8400 & 1.16 \\
\hline $\mathrm{PSSV}_{3 \mathrm{k}}$ & 5000 & 3400 & 12000 & 10100 & 1.18 \\
\hline $\mathrm{PSSV}_{6 \mathrm{k}}$ & 5000 & 5900 & 14500 & 12900 & 1.12 \\
\hline $\mathrm{PSSV}_{9 \mathrm{k}}$ & 5000 & 8700 & 17800 & 15400 & 1.17 \\
\hline $\mathrm{PCCV}_{6 \mathrm{k}}$ & 5000 & 6100 & 19300 & 16800 & 1.13 \\
\hline
\end{tabular}

${ }^{\text {a }}$ The molecular weight of hydrophobic block was determined from ${ }^{1} \mathrm{H}$ NMR in DMSO- $\mathrm{d}_{6}$;

${ }^{b}$ The weight average molecular weight $(\mathrm{Mw})$, number average molecular weight and molecular weight distribution (PDI) were determined by gel permeation chromatography (mobile phase: DMF containing $20 \mathrm{mM}$ lithium bromide; elution speed: $1.0 \mathrm{~mL} / \mathrm{min}$ ). 
Table S2 The physicochemical characterization of ${ }^{\mathrm{SS}} \mathrm{SN} 38$ and ${ }^{\mathrm{Ss}} \mathrm{GA}$ NPs.

\begin{tabular}{lccl}
\hline Sample & Diameter & Zeta potential & SN38 loading \\
& $(\mathrm{nm})$ & $(\mathrm{mV})$ & Content $(\mathrm{wt} \%)$ \\
& & & \\
\hline $\mathrm{Ss} \mathrm{SN} 38$ & $33.6 \pm 2.5$ & $-6.8 \pm 1.1$ & 2.3 \\
\hline${ }^{\mathrm{Ss}} \mathrm{GA}$ & $45.7 \pm 4.9$ & $-8.9 \pm 1.7$ & 36.6 \\
\hline
\end{tabular}

\section{REFERENCES}

1. Yan, X.; Yu, Q.; Guo, L.; Guo, W.; Guan, S.; Tang, H.; Lin, S.; Gan, Z., Positively Charged Combinatory Drug Delivery Systems against Multi-Drug-Resistant Breast Cancer: Beyond the Drug Combination. ACS Applied Materials \& Interfaces 2017, 9, 6804-6815.

2. Luo, K.; Guo, W.; Yu, Y.; Xu, S.; Zhou, M.; Xiang, K.; Niu, K.; Zhu, X.; Zhu, G.; An, Z.; Yu, Q.; Gan, Z., Reduction-Sensitive Platinum (IV)-Prodrug Nano-Sensitizer with an Ultra-High Drug Loading for Efficient Chemo-Radiotherapy of Pt-Resistant Cervical Cancer in Vivo. J. Control. Release 2020, $326,25-37$.

3. Alferiev, I. S.; Iyer, R.; Croucher, J. L.; Adamo, R. F.; Zhang, K.; Mangino, J. L.; Kolla, V.; Fishbein, I.; Brodeur, G. M.; Levy, R. J.; Chorny, M., Nanoparticle-Mediated Delivery of a Rapidly Activatable Prodrug of SN-38 for Reuroblastoma Therapy. Biomaterials 2015, 51, 22-29. 